\title{
Modern pharmacognosy: Connecting biology and chemistry ${ }^{\star, \star *}$
}

\author{
Lars Bohlin $¥$, Ulf Göransson, and Anders Backlund \\ Division of Pharmacognosy, Department of Medicinal Chemistry, Faculty of \\ Pharmacy, Uppsala University, Box 574, S-751 23 Uppsala, Sweden
}

\begin{abstract}
In many countries today, the number of students selecting chemistry for higher studies is decreasing. At the same time, interest in the environmental aspects of chemistry, green chemistry, and sustainable use of natural products is increasing among the young generation of students. By modernizing and renewing a venerable proven science, pharmacognosy would have a strategic position to connect biology and chemistry. This multidisciplinary subject is important for discovery of novel and unique molecules with drug potential, and for revealing unknown targets, by studying evolutionary structure-activity optimization in nature. In this paper, the overall aim and strategies of our research are presented and exemplified by three different research projects.

Natural products are involved in scientific issues important for a sustainable society, and a multidisciplinary subject such as pharmacognosy can, therefore, be useful in increasing future interest in both chemistry and biology.
\end{abstract}

Keywords: pharmacognosy; prediction of selection; cyclotides; cytoxicity; marine sponges; antifouling.

The decrease in the number of students pursuing higher studies in chemistry is an international trend. In a recent editorial in Science, education in chemistry and other science subjects was discussed, with emphasis on the situation in the United States [1]. It was noted that the educational methods were oldfashioned and also, that the number of students in each class was very high. As a result, many students did not pursue their studies in subjects like chemistry. At the same time, the importance of the environment, green chemistry, and the sustainable use of natural products is evident in the younger generation of students.

It is obvious that something must be done to increase interest in the scientific disciplines, to enable us to handle the complexity and number of science-based problems in the future. In the university setting, educational programs need to be developed in many different ways. One way would be to blend different disciplines and teach about complex questions in society in a multidisciplinary way and in this way revitalize scientific education. By using such a holistic approach, the science teaching would probably be more exciting for students. In fact, this is a proven concept: During the $18^{\text {th }}$ century, the famous Swedish scientist Linnaeus used a holistic approach in his scientific work and teaching. Linnaeus even wrote numerous theses for dissertations in different disciplines, including interdisciplinary works such as Medicamenta graveolentia (Drugs with a strong smell), Sapor medicamentorum (The taste of drugs),

\footnotetext{
*Pure Appl. Chem. 79, 467-823 (2007). An issue of reviews and research papers based on lectures presented at the $25^{\text {th }}$ International Symposium on Chemistry of Natural Products (ISCNP-25) and $5^{\text {th }}$ International Conference on Biodiversity (ICOB-5), held jointly in Kyoto, Japan, 23-28 July 2006, on the theme of natural products.

**In honor of Professors Emeritii Finn Sandberg and Gunnar Samuelsson.

¥Corresponding author
} 
De methodo investigandi vires medicamentorum chemica (Regarding the chemical method to investigate the virtues of drugs), and Ineberiantia (Intoxicants). In 1749, he published his Materia Medica, which has as its focus the multidisciplinary approach of combining botany with medicine in the discovery of the medical potential in nature. A chair of Materia Medica was established in Linneaus' time. It has since been renamed as pharmacognosy and for a long time belonged to Karolinska Institute. Today, the chair in pharmacognosy is housed at the Faculty of Pharmacy at Uppsala University.

In this review, we describe our current research in the subject of pharmacognosy, which we consider to be a good example of a modern multidisciplinary discipline that could serve to stimulate the interest in science.

Increased interest in the study of natural products in drug development, as well as rapidly changing research strategies, are driving forces in the modernizing of pharmacognosy [2,3]. The term "modern" in this context means at all times description of a science that uses state-of-the art techniques and competence to contribute to the development of science. Pharmacognosy today focuses on the discovery of novel and unique molecules and on revealing unknown targets by studying the evolutionary structure-activity optimization of such molecules in nature. As such, pharmacognosy is one of several scientific disciplines that have a strategic position in connecting biology with chemistry and even medicine. New and improved strategies concerning selection of organisms, bioassays, isolation procedures, and structure elucidation are continuously developed based on the latest advancements in science.

\section{PROSPECTING BIODIVERSITY}

Emerging trends in, and unrealized expectations from, current research and development strategies are prompting renewed interest in natural products as a source of chemical diversity for lead generation [4]. Several different strategies based on ethnopharmacological, ecological, or toxicological observations are used in prospecting the biodiversity of nature in the search for novel biological activity and chemical structures.

It is likely that many millions of chemically distinct molecules exist in nature, probably many more than there are different biological functions. This leads to an intriguing question: For the important molecular targets in the human body, do biologically active compounds exist also in other species, and in more than one particular species [5]? Traditionally, research on natural sources was focused on terrestrial plants and microorganisms, and more recently also on organisms of marine origin. However, would it be of value to use unconventional and hardly explored sources that have never been systematically explored in pharmacological assays [6]? Invariably, already known compounds are rediscovered and regarded mostly as "nuisance" and therefore discarded. However, rediscovery of a known compound that shows an unknown mechanism of action in yet another, distantly related species, could point to a new and important biological function by interacting with a specific molecular target [7]. The complex biomass in functional/medical food or herbal remedies and the proposed healthy effects need attention and multidisciplinary collaboration. Perhaps the novel systems biology approaches, and metabolomics, will open up the enigmatic subtleties of interactions between substances and healthy or diseased organisms [8].

\section{HOST DEFENSE}

Studies on host defense in plants and animals have resulted in discovery of similarities between pathogen recognition, signal transduction pathways, and effector mechanisms. For example, the lipidbased signaling cascades in mammals and plants produce analogous substances: In mammals, the cascade begins with arachidonic acid, which transforms into prostaglandins, while in plants, the system transforms linolenic acid into phytodienoic acid and jasmonic acid [9]. It has been shown that both cascades are mediated by homologous enzymes, cyclooxygenase (COX) enzymes in mammals and 
pathogen-induced oxygenase (PIOX) in plants [10]. Based on these results, it has been suggested that innate immunity is an ancient evolutionary defense mechanism [11]. The similarity between the plant and animal defense system motivates an intensified search for factors in plants with possibilities for applications in the mammalian (i.e., human) system, for example, with activity in the inflammatory process or in the innate immune system.

The way proteins and peptides are produced by many organisms, from plants and insects to human beings, as an important part of their immediate, nonspecific defense against infections, is another example of such similarity [12]. Plants, insects, and humans are evolutionarily not too distant and have diversified for only less than a billion years. Thus, it is argued that they share similarities in their ancestral innate defense systems [13]. One kind of ancestral defense proteins, called "defensins", are $3-5 \mathrm{kDa}$ in size, basic, and rich in cysteine. Four defensins from the human defensin family are known to be expressed in neutrophils, namely, human neutrophil peptides 1-4 (HNP1-4) [14]. In vitro, these defensins kill bacteria, fungi, and some enveloped viruses [15]. In addition, they also display activity against human tumor cell lines $[15,16]$.

Defensins are common also in plants, often together with small proteins such as lectins, thionins, and cyclotides, all of which have been suggested to form parts of plants' innate immune defense. These polypeptides have evolved under evolutionary pressure, which with time has almost certainly resulted in structural optimizations to fulfill important biological functions and meet important needs of plants. Although these functions are not yet fully understood, it does seem that these structurally complex plant polypeptides are involved in plant host defense [17].

Our research strategy, which is focused on peptides involved in defense of plants and animals, is here exemplified by three research projects: bioactive plant cyclotides, antifouling dipeptides of marine origin, and prediction models for selection of organisms.

\section{BIOACTIVE PLANT CYCLOTIDES}

Cyclotides are a recently discovered family of plant proteins that probably have a general functional role in planta similar to the defensins, namely, host defense. Their structural basis, however, is different; in fact, the cyclotides form a unique family of circular proteins. As shown in Fig. 1, their N- and C-termini are joined by an ordinary peptide bond. In combination with three disulfide bonds, the seamless protein backbone confers extraordinary stability [18]. Currently, cyclotides form the largest known family of circular proteins and different cyclotides have shown a variety of biological effects [19-21]. We have been involved in cyclotide research for the last 10 years, and in our ongoing project we aim to explore possibilities to capitalize on these circular proteins, their activity and biosynthesis, and the fact that they constitute an extraordinarily stable platform for protein engineering.

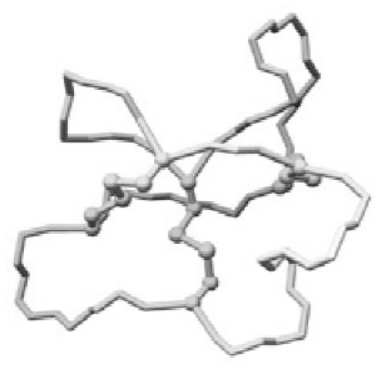

Fig. 1 Schematic representation of the cyclotide structure, showing the circular backbone and cystine knot (disulfide bonds in ball and stick mode). These features define the cyclic cystine knot (CCK) motif. 
The original discovery of cyclotides dates back to the 1970s, and is a fascinating example of how ethnopharmacology has provided a structurally unique class of lead molecules with possible applications in both medicine and agriculture. Two independent observations were made of the use of a decoction of the African plant Oldenlandia affinis (Rubiaceae) to facilitate childbirth [22]. In Congo, the Norwegian Red Cross physician Lorents Gran encountered a high frequency of complicated deliveries due to use of this plant, which was locally known as Kalata-Kalata [23,24]. Triggered by this observation, he brought the plant back to Norway, where he isolated the first cyclotide, the uteroactive Kalata B1, as part of his doctoral thesis. However, the complete sequence and cyclic structure were not determined until more than 20 years later [25]. In 1999, as additional cyclotides were discovered, our group and others recognized them as a new protein family [26,27]. At that time, they were given the name "cyclotides" and their unique structure was defined as the cyclic cystine knot (CCK) motif [27].

In addition to inducing contraction of the uterus, cyclotides have shown a variety of other biological activities. For example, cyclotides have been discovered to have insecticidal [28], antifouling [29], antimicrobial [30], and HIV-inhibitory [31] effects. Recently, we showed that cyclotides also have potent and selective cytotoxic activity [32,33]. Cyclotides are cytotoxic in the same concentration range as anticancer drugs used today, but their activity profile indicates a different mode of action than any clinically used drug. Activity is also observed in solid tumors, for which many forms of established chemotherapeutic drugs are ineffective. In addition, potency and selectivity are dependent on the structure of the tested cyclotides. For example, a single glutamic acid residue plays a key role in the activity [34].

The mechanism of action of cyclotides is, however, still unknown. One plausible mechanism involves membrane interactions and pore formation through the cell membranes: This theory could possibly explain several of the reported effects. This theory is supported by the fact that cyclotides have affinity for lipid formulations in surface plasmon resonance experiments [35]. In addition, it has also been proposed that the antimicrobial effects previously described in the literature [30] are due to electrostatic interactions, most likely between cationic amino acid residues and anionic lipids in the membranes.

To date, more than 80 cyclotides have been reported from species of three plant families, the Violaceae, Rubiaceae, and Cucurbitaceae. The Violaceae plant family seems to be particularly rich in these proteins [36-38], and single Violaceae species may contain more than 60 different cyclotides. It has been suggested that there may be $>9000$ cyclotides in the Violaceae plant family alone [38]. Figure 2 highlights the fact that the cyclotides fall into two major subfamilies, which are called "bracelet" and "Möbius" (so named because of a twist in the circular backbone). Notable amongst the sequences are the six conserved cysteine residues. As shown in Figs. 1 and 2, they are arranged in a knot, with two disulfide bonds forming a ring together with their connecting protein backbone, which is threaded by the third disulfide bond $[25,39,40]$. The sequences between the cysteines, the loops, are more or less variable. This pattern of variable and conserved loops in cyclotides raises several questions. For instance, which part of the sequence is crucial for the cyclotide core structure, and which parts are exchangeable, i.e., possible targets for protein engineering? Also, to what degree may the loops be varied before the structure collapses? To answer these questions, it is crucial to understand their structural diversity and origin in nature. To this end, we have invested great effort into the development of methods specifically aimed at cyclotide analysis. This includes extraction protocols for plant polypeptides [41], and chromatographic methods for separation of the complex cyclotide cocktails found in the plant [26,36], and their structural characterization [39]. 


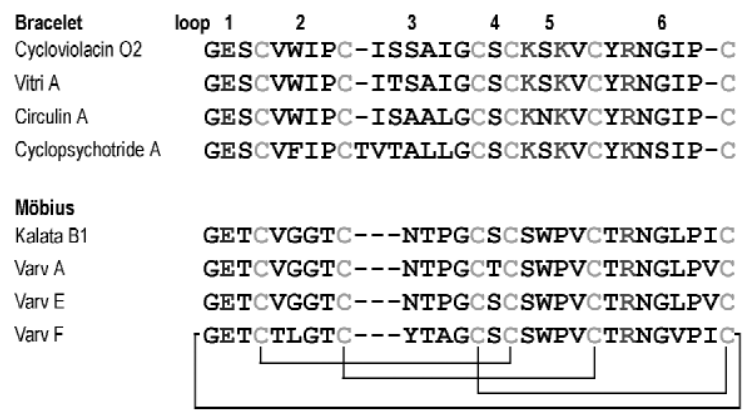

Fig. 2 Representative cyclotide sequences from the bracelet and Möbius subfamilies. Note the pattern of conserved and variable sequence loops. Brackets show the cyclic backbone and the disulfide bonds.

A key to understanding the cyclotides' structure and occurrence is understanding their biosynthesis. Today, we know that cyclotides are true gene products, which are expressed as precursor proteins [28]. However, not much is known about the processing of this precursor. Is the cyclization process catalyzed enzymatically or based on automatic excision and ligation of the free termini? Which elements in the sequence control the cyclization and folding? Are the disulfides formed before or after the cyclization - and in which order are they formed to yield the native form? These are all questions that remain to be answered.

Taken together, the demonstrated biological activity of the cyclotides makes them very appealing for further development, for example, as anticancer, anti-HIV, and insecticidal agents. Given their extraordinary stability and their ability to carry highly variable stretches of sequences within this stable framework, cyclotides have also become a prime target as a platform for protein engineering [21,42]. What is important for these applications are the possibilities for both chemical synthesis and cell-based production systems that have recently been reported $[43,44]$.

\section{ANTIFOULING MARINE DIPEPTIDES}

Large areas of the seabed in the North Atlantic are covered with reef-like fields of sponges (Porifera), some of which are several thousand years old [45]. Sponge fields are known to be important hotspots of marine biodiversity $[46,47]$ and serve as refuges as well as hunting grounds for a number of species, including commercial fish [48]. The sponges building up this biotope, mainly Geodia barretti, Geodia macandrewii, Geodia atlantica, Isops phlegraei, and Stryphnus ponderosus, are large (weighing up to $25 \mathrm{~kg}$ ) and, like coral reefs, form a complex, three-dimensional habitat. They may be considered ecological engineers modifying the seabed habitat and should be regarded as key species in deep-sea communities. These sponges are characterized by a long life span, slow growth, and low recruitment, and are therefore sensitive to changes in their environment [49]. The deeper parts of the Swedish west coast also harbor communities of deep-water sponges of the same key species as mentioned above [45].

Sponges produce a large part of all known marine secondary metabolites [50]. The adaptive significance of these secondary metabolites is often unclear, and traditionally, they have been regarded as evolutionarily neutral or as waste products-biosynthetic dead-ends. However, the currently most accepted view is that most (probably virtually all) secondary metabolites have an adaptive, evolutionary value and play key roles in the defense against pathogens, parasites, predators, competitors, and biofouling (as reviewed by Harper et al. [50]).

The observation that the marine sponge G. barretti, which is found in the Norwegian fjords and in the Swedish Koster Fjord, possesses an almost entirely fouling-free body surface (Fig. 3) prompted us to study a possible chemical defense against growth of other living organisms. We demonstrated that G. barretti produces at least two congeneric cyclopeptides, barettin and 8,9-dihydrobarettin, with strong 
inhibitory effects on settling stage larvae of the barnacle Balanus improvisus [51]. Settlement of larvae was inhibited in a dose-dependent manner without any significant lethal effects in concentrations ranging from 0.5 to $25 \mu \mathrm{M}$ (Fig. 4). In addition to these laboratory tests, a field test showed that both barettin and 8,9-dihydrobarettin also significantly inhibit settlement of the blue mussel Mytilus edulis [52].

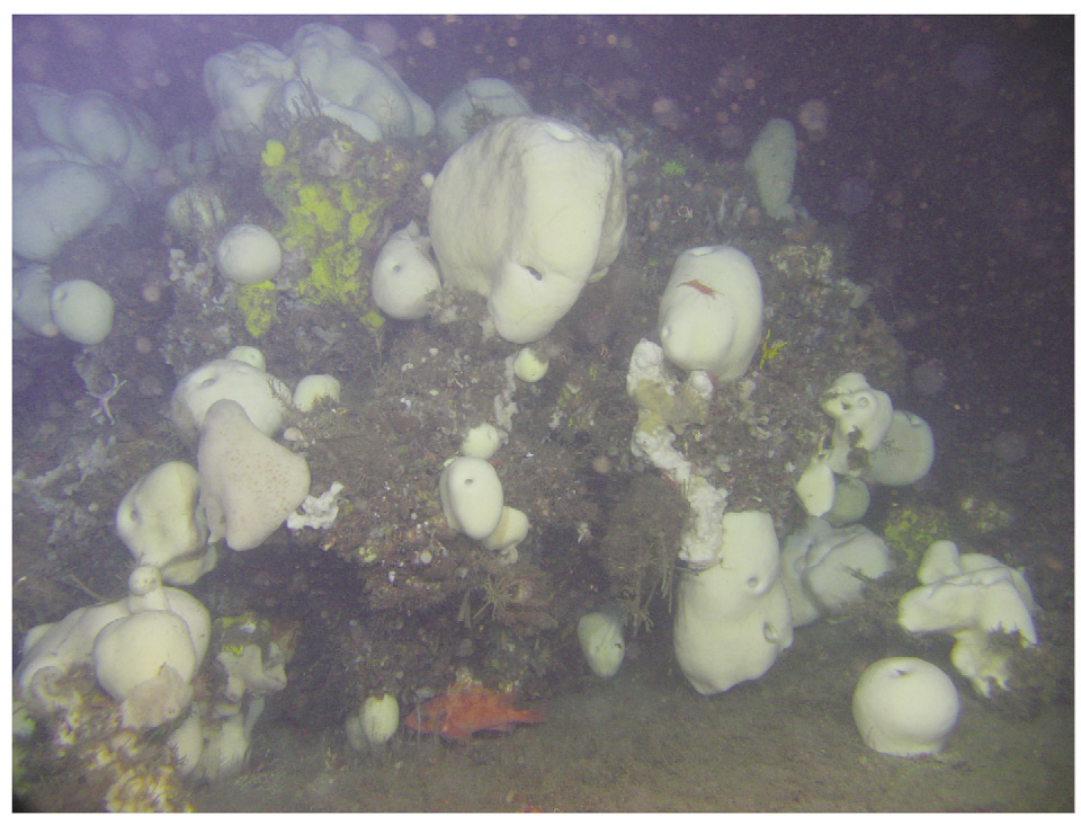

Fig. 3 Sponge reef with G. barretti at a depth of $123 \mathrm{~m}$ in the Koster channel on the west coast of Sweden (Photo Thomas Lundälv, Tjärnö Marine Biology Laboratory).

\section{a) Barettin}<smiles>N=C(N)NCCCC1NC(=O)C(=Cc2c[nH]c3cc(Br)ccc23)NC1=O</smiles>

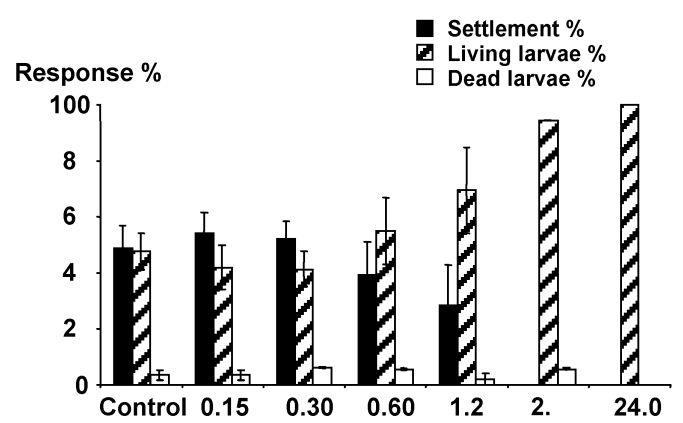

b) 8,9-dihydrobarettin<smiles>N=C(N)NCCCC1NC(=O)C(Cc2c[nH]c3cc(Br)ccc23)NC1=O</smiles>

Settlement \% $\begin{array}{ll}\text { Response \% } & \text { Living larvae \% } \\ & \square \text { Dead larvae \% }\end{array}$

Fig. 4 Effect of (a) barettin and (b) 8,9-dihydrobarettin on the settlement of cyprid larvae of B. improvisus [15]. 
In order to further establish the molecular target and mode of action of the barettins, we investigated their affinity to human serotonin receptors. G protein-coupled receptors (GPCRs) are found in simple eukaryotes, such as yeasts and molds, as well as in invertebrates, vertebrates, and mammalians [53]. GPCRs are membrane-bound receptors that are highly conserved in their structure and share a similar, basic protein platform (reviewed in ref. [54]). GPCRs are the main receptors to which the biogenic amines bind to exert their action. Together, barettin and 8,9-dihydrobarettin display particular affinities for three subtypes of a mammalian serotonin GPCR (barettin: 5-hydroxytryptamine 5- $\mathrm{HT}_{2 \mathrm{~A}}$, 5- $\mathrm{HT}_{2 \mathrm{C}}$, and 5- $\mathrm{HT}_{4} ; 8$,9-dihydrobarettin: 5- $\mathrm{HT}_{2 \mathrm{C}}$ ) [55].

In conclusion, identification of the marine cyclodipeptides barettin and 8,9-dihydrobarettin as selective serotonin receptor ligands may prove useful in further defining the functional roles of 5-HT receptors in invertebrates. Moreover, the small difference in chemical backbone between barettin and 8,9-dihydrobarettin results in striking differences in affinity to the human 5-HT receptors. To gain further knowledge about the structure-activity basis of the shown antifouling activity and effect on receptor levels, several analogs were designed and synthesized and resulted in novel analogs with improved activity [56].

\section{STRATEGIES FOR SELECTION}

The two research projects described above are examples of two different observations in nature based on ethnopharmacological and ecological data, respectively, which guided both the selection of organisms and the applied research strategy.

This highlights that among the most important and critical decisions made, in virtually any scientific endeavor, is the selection of the objects to study. In the field of pharmacognosy, this often implies the selection of living organisms or the chemical substances originating from these. Traditionally, the application of ethnopharmacological data in these selection processes has been of outmost importance, but with the increasing knowledge regarding the origins and development of life, as well as with mathematical and technological breakthroughs, a new set of data is at hand to assist us in making intelligent choices in the vast diversity presented by nature.

In a way, the result of evolutionary processes can be regarded to form an evolutionary space, populated by extant and extinct organisms. This space has for the last 50 years been the subject of extensive mapping. While initially employing various stratagems (including principal component analysis), these efforts have now taken the form of phylogenetic studies aimed at elucidating evolutionary relationships. This is, in many cases, done using nucleotide or amino acid sequence data, providing robust results for various groups of organisms. Phylogenies, i.e., hypotheses of evolutionary relationships, have during the last 20 years emerged as a powerful concept in the life sciences, with regard to their explanatory power [57]. One of the greatest advantages of phylogenies, as compared with the older, synoptic classification, is that they enable also a predictive perspective. This is one aspect of what we attempt to explore and utilize in the selection of study objects, always in search of bioactive compounds, their origin, evolution, and distribution.

There are numerous different ways in which phylogenies may contribute to the selection process. Among the more obvious, we can see a possibility to ensure adequate coverage of different evolutionary groups, to pinpoint underrepresented groups, find the closest relative to a specific group, increase hit rates by choosing objects to study from groups with a promising "track record", and increase the chance of finding new, different molecules by avoiding groups that have been previously sampled.

Natural products, in one respect, form a mirror image of evolutionary processes, as pointed out by Abbot already in 1887 [58]. In recent years, attempts have been made to grasp the huge number of known chemical compounds, resulting in consistent mapping devices for the drug-related chemical space, such as the chemical global positioning system ChemGPS [59]. Studies have, however, demonstrated the inadequacy of this model for handling the diversity of natural products chemistry [60]. This 
observation triggered the development of a device tuned for explorations of the biologically relevant regions of chemical space [61].

This tool, a map of the natural products chemical space, known as "ChemGPS-NP" [61], was developed using the same principles as applied to the original ChemGPS, but with a significantly larger scope. Initially based on SMILES representations (compact one-line alphanumerical strings) of more than 120000 structural formulae, a model was constructed based on more than 900 physical-chemical descriptors. From the model, successive predictions of positions in natural products chemical space were made for more than 1 million compounds. With rigorous control of the predicted compounds deviating from the model, the latter was successively expanded until no further outliers were found. The resulting ChemGPS-NP therefore forms a representation of all at the time compilable natural products-a global map.

As outlined by Larsson et al. [61], this map of the natural products chemical space differs from previously published versions of the so-called "drug-like space" [59]. Most notably, the major dimensions of the map are arranged in a different order, interpretable as reflecting differences in strategies between medicinal chemists and evolutionarily affected biosynthesis. With the present design, the ChemGPS-NP map is focused on secondary metabolites and small polypeptides, with the heaviest satellites included at ca. $4 \mathrm{kDa}$. This dimension, however, is the only one in which a cutoff value has deliberately been defined; in all other dimensions, the most extreme natural products have been included and predicted. Although extrapolation of the map in directions "outside" the present satellites is fully possible, the precision of the predictions will eventually decrease as the outlier's distance to the model increases.

When predicting the enigmatic set of COX inhibitors in Larsson et al. [60], the importance of a relevant model is evident. Not only are all predicted molecules well described within the model, in contrast to the original ChemGPS, but also, strong clustering patterns are discernable from the plots [61].

While sharing many similarities, there is one important conceptual difference between evolutionary and chemical space. The organisms populating the former are results of one single, common, history of evolutionary events. The compounds in the latter, on the other hand, are the products of a partly reticulate pattern of biosynthetic pathways, hence justifying a multidimensional map. On this path, we take a step further to fuse chemical with evolutionary spaces, by applying ChemGPS-NP to predict chemical traits of natural products with a limited distribution in the phylogeny of living organisms. One purpose of these comparisons is to test hypotheses of secondary metabolite evolution with an emphasis on their change in their physical-chemical properties. This provides us with a framework not only to identify compounds (and their mother organisms) with sought properties, but also to actively test proposed hypotheses or in an objective manner compare compounds from two different sources or studies. The only data needed to discuss "differences and similarities" would be the compound's structural formulae, and we would then not be restricted by what structural elements that happen to feast our eyes. Several different examples, based on biosynthetically separated plant metabolites, have been evaluated in our studies, and we will here describe two of these.

\section{Betalains}

Consisting of only ca. 50 members, this small group of compounds is found in 9 of the 11 families of the plant order Caryophyllales. In these, the betalains constitute coloring pigments, while in most other plants, the pigments are anthocyanins [e.g., 62]. Despite their small number and apparent structural homogeneity, the betalains span a comparably large sector of the chemical property space. Betalains have several applications, both in alimentary industry and, more recently, in pharmaceutical studies, and their biosynthesis has been thoroughly investigated. The two biosynthetic groups, betacyanidins and betaxanthins, are clearly separated by their physical-chemical properties. The latter group also divides into two distinct clusters, based on size and polarizability of their amino acid moeity. The muscaflavins, found as pigments in species such as the toadstool, Amanita muscaria, have on biosynthetic grounds 
been suggested to be "chemical relatives" of the betalains [63]. In our study, two muscaflavins included are predicted as members of the "heavy unpolar betaxanthin cluster" (Fig. 5).

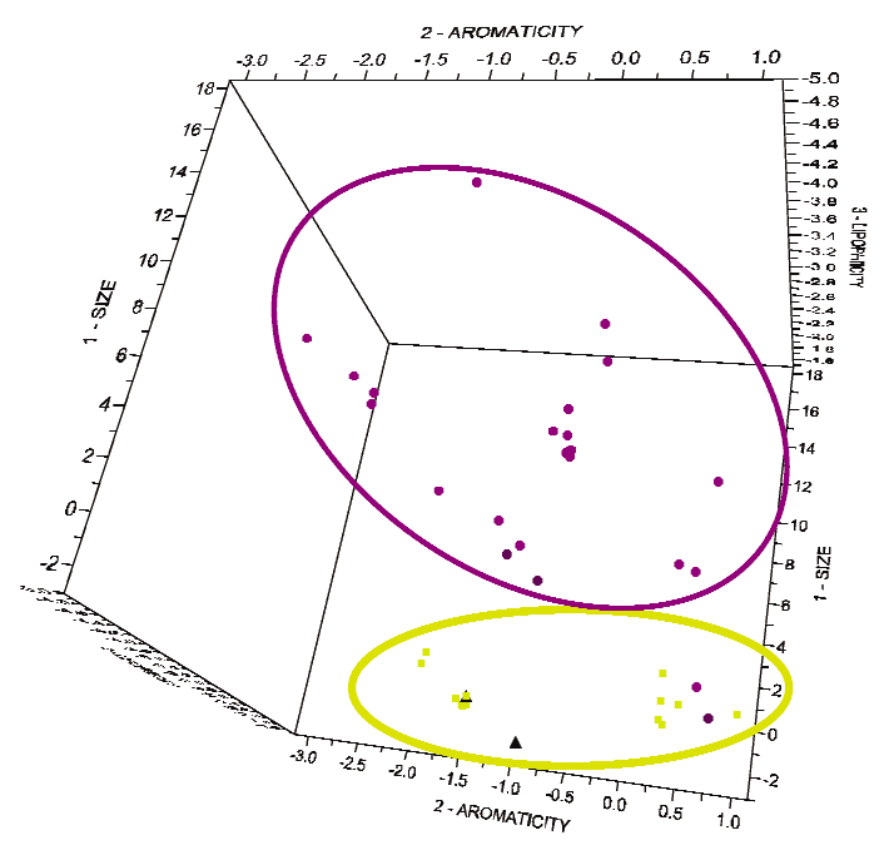

Fig. 5 The two well-defined biosynthetic groups of betalains: betacyanidins labeled with purple dots $\bullet$ and betaxanthins by yellow squares a are clearly separable by their physical-chemical properties. The latter also divides in two distinct clusters, due to size and aromaticity of their amino-acid moeity. The muscaflavins, found as pigments in, e.g., the toadstool A. muscaria, have on biosynthetic grounds been suggested as "chemical relatives" of the betalains. In this study, two muscaflavins $\boldsymbol{\Delta}$ included are predicted as members of the "heavy unpolar betaxanthin cluster".

\section{Iridoids}

With $>1500$ known members, the iridoids have been frequently investigated in plant chemosystematic studies, beginning with Dahlgren in the 1970s [64 and refs. therein]. Apart from aberrant reports on insects, for example, the main distribution of iridoids is in the subclass Asteridae of the flowering plant. The spurious absence in some families is now evolutionarily interpreted as a secondary loss of the ability to synthesize iridoids. The frequently discussed and presumably important difference between the iridoid biosynthesis routes I and II is not clearly reflected from estimated physical-chemical properties of the 357 iridoids included in this study (Fig. 6). However, two prominent clusters can be discerned, corresponding primarily to the size and complexity of side chains. Within the subclass Asteridae, there exist two main evolutionary lineages, commonly referred to as "the euasteridae I and II" [57]. The majority of iridoid compounds identified are found in the euasteridae I; of those from the euasteridae II, most belong in the cluster with less complex side chains. One of these groups is the valepotriates, forming a small subcluster with pronounced lipophilic properties. 


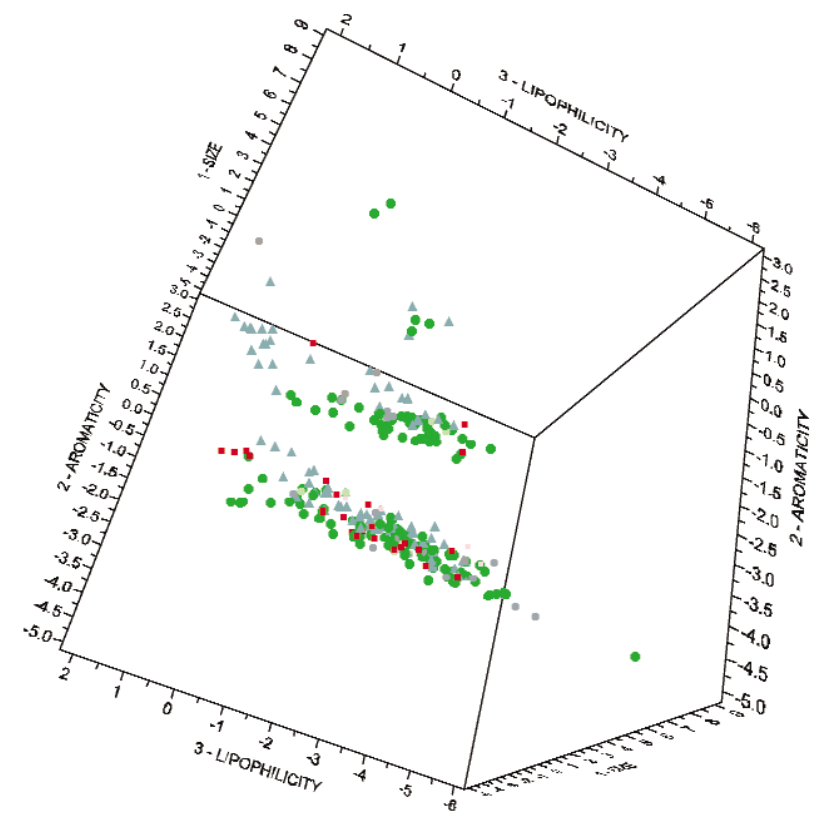

Fig. 6 The frequently discussed and presumably important difference between iridoids formed via the biosynthesis routes I, labelled with dots $\bullet$ and II, with triangles $\Delta$ is not clearly reflected from estimated physical-chemical properties of the 357 iridoids included in this study. Two prominent clusters can be discerned, corresponding primarily to the size and complexity of side-chains. Within the subclass Asteridae, there exists two main evolutionary lineages, commonly referred to as the euasterids I and II. The majority of iridoid compounds identified are found in the euasterid I, and of these from the euasteridae II $\bullet$ most belong in the cluster with less complex side chains.

\section{CONCLUSION}

From its beginning in the 1960s, cyclotide research has spanned the whole spectrum of the life sciences, from the use of the native medicine to state-of-the-art pharmacology and biotechnology, and from basic chemistry to cutting-edge structural biology. Consequently, this project is an excellent example of one of the most appealing features of pharmacognosy, namely, that it is truly multidisciplinary in nature. Ecological observations in the marine environment face a challenge to understand the functional role of secondary metabolites. However, the results from the described marine project suggest, apart from an antifouling potential, a possible function for the identified antifouling compounds as templates to provide clues in drug discovery research aimed at disease states associated with the serotonergic system. For the future, observations in nature based on ethnopharmacological and ecological data will continue to be a part of the platform for selection of organisms for further in-depth studies. However, with the use of phylogenetics and the development of chemography, providing a consistent chemical mapping device, the ChemGPS seems to be a future possibility to assist us in making intelligent choices in the vast diversity presented by nature.

One of the major objectives of the future society is to build a competitive, knowledge-based economy. A crucial part of this process is to strengthen the science base. A decrease in the number of students pursuing higher studies in science is an international trend. If this trend continues, it will lead to a population, including our politicians and decision-makers at different levels, that will have very limited knowledge of science. This could have serious effects on important decisions that must be taken in the near future about global warming, intelligent design, stem cell research, and other issues connected to science and nature. 


\section{ACKNOWLEDGMENTS}

The authors are grateful for economic support from the Swedish Research Council of Environment, Agricultural Sciences, and Spatial Planning. Furthermore, all graduate students and other collaborators in the different projects are acknowledged.

\section{REFERENCES AND NOTES}

1. T. Cech, D. Kennedy. Science 310, 1741 (2005).

2. J. G. Bruhn, L. Bohlin. Drug Discov. Today 2, 243 (1997).

3. P. Claeson, L. Bohlin. Trends Biotechnol. 15, 245 (1997).

4. F. E. Koehn, G. T. Carter. Nature Rev./Drug Discov. 4, 206 (2005).

5. M. Tulp, L. Bohlin. Trends Pharmacol. Sci. 23, 225 (2002).

6. M. Tulp, L. Bohlin. Drug Discov. Today 9, 450 (2004).

7. M. Tulp, L. Bohlin. Bioorg. Med. Chem. 13, 5274 (2005).

8. M. Tulp, L. Bohlin. Drug Discov. Today 11, 1115 (2006).

9. D. R. Bergey, G. A. Hoi, C. A. Ryan. Proc. Natl. Acad. Sci. USA 93, 12053 (1996).

10. A. Sanz, J. L. Moreno, C. Castresana. Plant Cell 10, 1523 (1998).

11. J. A. Hoffmann, F. C. Kafatos, C. A. Janeway, R. A. B. Ezekowitz. Science 284, (1999).

12. R. E. W. Hancock. Lancet Infect. Dis. 1, 156 (2001).

13. N. Borregaard, P. Elsbach, T. Ganz, P. Garred, A. Svejgaard. Immunol. Today 21, 68 (2000).

14. T. Ganz, R. I. Lehrer. Curr. Opin. Immunol. 6, 584 (1994).

15. R. I. Lehrer, A. K. Lichtenstein, T. Ganz. Annu. Rev. Immunol. 11, 105 (1993).

16. A. Bateman, A. Singh, S. Jothy, R. Fraser, F. Esch, S. Solomon. Peptides 13, 133 (1992).

17. P. Thomma, B. P. Cammue, K. Thevissen. Planta 216, 193 (2002).

18. M. L. Colgrave, D. J. Craik. Biochemistry 43, 5965 (2004).

19. U. Göransson, E. Svangård, P. Claeson, L. Bohlin. Curr. Protein Pept. Sci. 5, 317 (2004).

20. D. J. Craik, N. L. Daly, J. Mulvenna, M. R. Plan, M. Trabi. Curr. Protein Pept. Sci. 5, 297 (2004).

21. D. J. Craik. Science 311, 1563 (2006).

22. L. Gran, F. Sandberg, K. Sletten. J. Ethnopharmacol. 70, 197 (2000).

23. L. Gran. Lloydia 36, 174 (1973).

24. L. Gran. Acta Pharmacol. Toxicol. 33, 400 (1973).

25. O. Saether, D. J. Craik, I. D. Campbell, K. Sletten, J. Juul, D. G. Norman. Biochemistry 34, 4147 (1995).

26. U. Göransson, T. Luijendijk, S. Johansson, L. Bohlin, P. Claeson. J. Nat. Prod. 62, 283 (1999).

27 D. J. Craik, N. L. Daly, T. Bond, C. Waine. J. Mol. Biol. 294, 1327 (1999).

28. C. Jennings, J. West, C. Waine, D. J. Craik, M. Anderson. Proc. Natl. Acad. Sci. USA 98, 10614 (2001).

29. U. Göransson, M. Sjögren, E. Svangård, P. Claeson, L. Bohlin. J. Nat. Prod. 67, 1287 (2004).

30. J. P. Tam, Y. A. Lu, J. L. Yang, K. W. Chiu. Proc. Natl. Acad. Sci. USA 96, 8913 (1999).

31. K. R. Gustafson, T. C. McKee, H. R. Bokesch. Curr. Protein Pept. Sci. 5, 331 (2004).

32. P. Lindholm, U. Göransson, S. Johansson, P. Claeson, J. Gullbo, R. Larsson, L. Bohlin, A. Backlund. Mol. Cancer Ther. 1, 365 (2002).

33. E. Svangård, U. Göransson, Z. Hocaoglu, J. Gullbo, R. Larsson, P. Claeson, L. Bohlin. J. Nat. Prod. 67, 144 (2004).

34. A. Herrmann, E. Svangård, P. Claeson, J. Gullbo, L. Bohlin, U. Göransson. Cell Mol. Life Sci. 63, 235 (2006).

35. H. Kamimori, K. Hall, D. Craik, M. Aguilar. Anal Biochem. 337, 149 (2005).

36. U. Göransson, A. M. Broussalis, P. Claeson. Anal. Biochem. 318, 107 (2003).

37. D. C. Ireland, M. L. Colgrave, D. J. Craik. Biochem J. 400, 1 (2006). 
38. S. M. Simonsen, L. Sando, D. C. Ireland, M. L. Colgrave, R. Bharathi, U. Göransson, D. J. Craik. Plant Cell 17, 3176 (2005).

39. U. Göransson, D. J. Craik. J. Biol. Chem. 278, 48188 (2003).

40. K. J. Rosengren, N. L. Daly, M. R. Plan, C. Waine, D. J. Craik. J. Biol. Chem. 278, 8606 (2003).

41. P. Claeson, U. Göransson, S. Johansson, T. Luijendijk, L. Bohlin. J. Nat. Prod. 61, 77 (1998).

42. D. J. Craik, M. Cemazar, N. L. Daly. Curr. Opin. Drug Discov. Devel. 9, 251 (2006).

43. P. Seydel, H. Dörnenburg. Plant Cell, Tissue Organ Culture 85, 247 (2006).

44. S. Gunasekera, N. L. Daly, M. A. Anderson, D. J. Craik. IUBMB Life 58, 515 (2006).

45. A. B. Klintgard, O. S. Tendal. Prog. Oceanogr. 61, 57 (2004).

46. J. N. A. Hooper, J. A. Kennedy, R. J. Quinn. Biodiversity Conserv. 11, 851 (2002).

47. J. L. Wulff. Biol. Cons. 127, 167 (2006).

48. P. J. Auster. Rev. Fish. Sci. 4, 185 (1996).

49. L. Waitling, E. A. Norse. Cons. Biol. 12, 1180 (1998).

50. M. K. Harper et al. Marine Chemical Ecology, J. B. Mc Clintock, B. J. Baker (Eds.), CRC Press, Boca Raton (2001).

51. M. Sjögren, U. Göransson, A. L. Johnson, M. Dahlström, R. Andersson, J. Bergman, L. Bohlin. J. Nat. Prod. 67, 368 (2004a).

52. M. Sjögren, M. Dahlström, U. Göransson, P. R. Jonsson, L. Bohlin. Biofouling 20, 291 (2004b).

53. S. J. Peroutka, T. A. Howell. Neuropharmacology 33, 319 (1994).

54. M. Dahlström, H. Elwing. Prog. Mol. Subcell. Biol. 42, 171 (2006).

55. E. Hedner, M. Sjögren, P. A. Frändberg, T. Johansson, U. Göransson, M. Dahlström, P. Jonsson, F. Nyberg, L. Bohlin. J. Nat. Prod. 69, 1421 (2006).

56. M. Sjögren, A. L. Johnson, E. Hedner, M. Dahlström, U. Göransson, H. Shirani, J. Bergman, P. R. Jonsson, L. Bohlin. Peptides 27, 2058 (2006).

57. APG II. Bot. J. Linn. Soc. 141, 399 (2003).

58. H. Abbot. The Chemical Basis of Plant Forms, Franklin Institute lecture (1887).

59. T. I. Oprea, J. Gottfries. J. Comb. Chem. 3, 157 (2001).

60. J. Larsson, J. Gottfries, L. Bohlin, A. Backlund. J. Nat. Prod. 68, 985 (2005).

61. J. Larsson, J. Gottfries, S. Muresan, A. Backlund. J. Nat. Prod. (2007). In press.

62. E. Grotewold. Ann. Rev. Plant Biol. 57, 761 (2006).

63. D. Strack, T. Vogt, W. Schliemann. Phytochemistry 62, 247 (2003).

64. G. Dahlgren. Davies \& Hedge Festschrift, University Press, Edinburgh (1991). 